over wider periods of time should be conducted for better understanding of TBI prevalence is highly recommended to develop effective injury prevention programmes in Egypt. Inefficient recording should raise the concern to establish an optimal system for data recording during disasters.

\section{THE 25TH OF JANUARY EGYPTIAN REVOLUTION'S EFFECT ON THE PREVALENCE OF TBI IN EGYPT. A RETROSPECTIVE COMPARATIVE STUDY}

doi:10.1136/injuryprev-2012-0405901.5

${ }^{1} \mathrm{~T}$ Montaser, ${ }^{2} \mathrm{~A}$ Al-Kafafy. ${ }^{1}$ Department of Emergency Medicine, Cairo University Hospital, Egypt; ${ }^{2}$ Department of Emergency Medicine, Alexandria University Hospital, Egypt

Background Traumatic Brain Injury (TBI) is a contributing factor to approximately one third (30.5\%) of all injury-related deaths in USA annually. Updated statistical records for TBI in Egypt are lacking.

Purpose The current research is aiming for estimating the prevalence of TBI in Egypt under different circumstances.

Methods A retrospective study was conducted to compare the prevalence of TBI during the revolution time in 2011(January 2011 until mid- February 2011) and the prevalence of TBI during the same time in 2010 .

Results The table below shows that overall incidence of TBI in January 2010 and 2011 was 487 and 471 cases respectively, of them $9.2 \%$ were moderate and severe TBI in the year 2010 and $27.8 \%$ in the year 2011. Regarding moderate and severe TBI, male sex was predominantly affected in both years 2010 and 2011, 75\% and 88\% respectively.

\begin{tabular}{|c|c|c|c|c|c|}
\hline & \multicolumn{2}{|c|}{$\begin{array}{c}\text { January-mid-February } \\
2010\end{array}$} & \multicolumn{3}{|c|}{ January-mid-February 2011} \\
\hline & FFH/MVC & Other causes & Gun shot/assault & FFH/MVC & Other causes \\
\hline TBI(all cases) & 407 & 80 & 117 & 324 & 30 \\
\hline $\begin{array}{l}\text { Moderate and } \\
\text { severe TBI }\end{array}$ & 38 & 7 & 88 & 35 & 4 \\
\hline
\end{tabular}

Significance TBI is a serious public health problem in Egypt under peace or violent conditions. While prevalence remains the same, severity and leading causes are varying. Further data interpretation 